\section{Dr. Jaime Campos Garrido}

\author{
Efraím Otero • Bogotá, D.C.
}

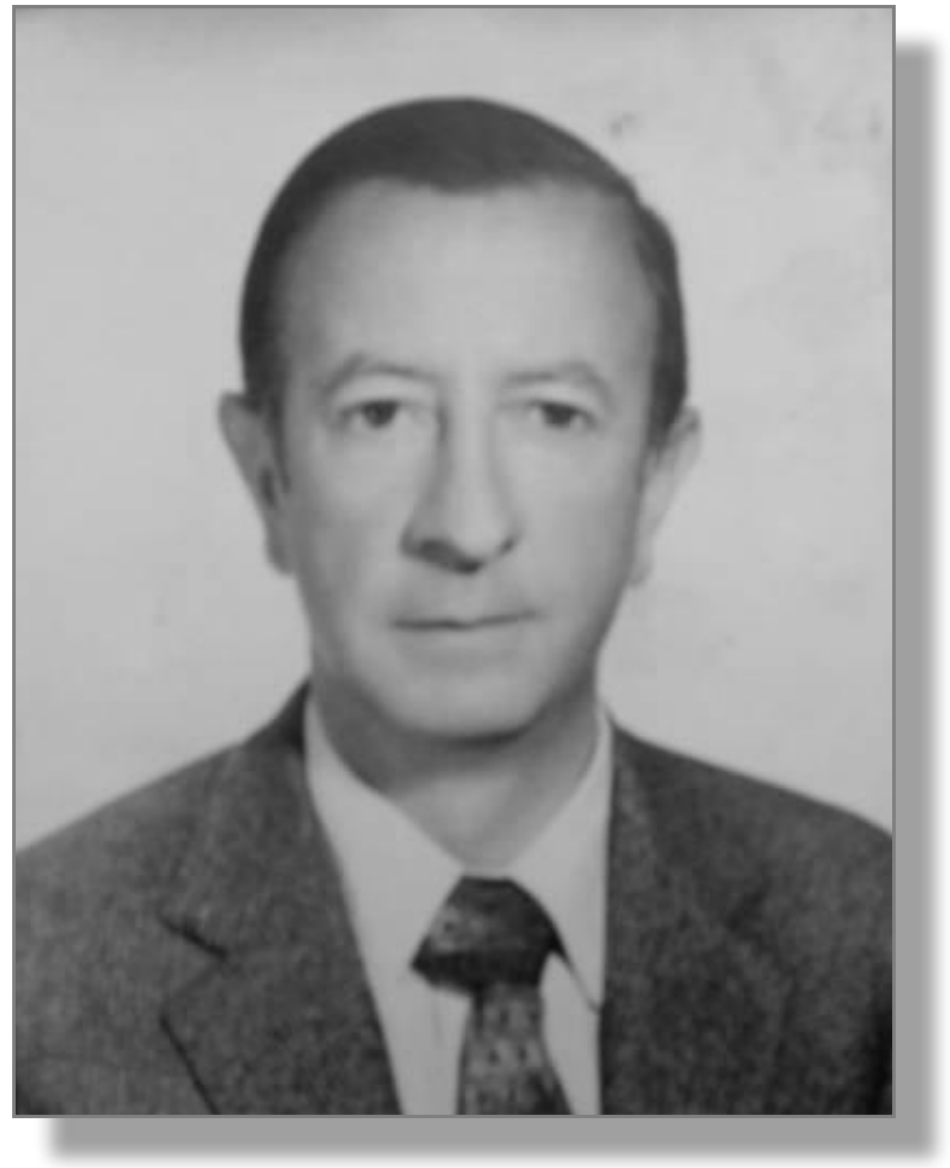

Dr. Jaime Campos Garrido (1939-2010).

Con el desgarramiento de las calamidades imprevistas y ahogados por la sorpresa y el dolor reprimido, nos agrupamos aquí hoy para decir unas palabras de despedida al inolvidable amigo y colega Jaime Campos Garrido. Porque quienes lo vieron a su regreso de Europa, hacía apenas un mes, jamás se imaginaron que la muerte iría a incluirlo en ese terrible listado que en el último semestre se ha llevado a lo mejor de la gastroenterología clínica y quirúrgica colombiana, en un desfile interminable de duelos sucesivos: Alvaro Caro Mendoza, Jaime De la Hoz y ahora Jaime, todos después de coronar las más brillantes carreras que la especialidad y la Universidad Nacional avalaron en la última mitad del siglo XX, y todos cercados de ese nimbo de prestigio y amistad que hoy nos hace más insoportable y dolorosa su partida.

Nacido de cuna preclara en Popayán, Jaime terminó sus estudios de médico en la Universidad Nacional en 1964 y desde sus épocas de estudiante mostró la inclinación por la que iría a ser su especialidad definitiva. Muy recién graduado viajó a Francia, donde iría a especializarse por varios años en endoscopia digestiva; allí fue pronto acogido por sus colegas que en etapas sucesivas lo irían incorporando a la Sociedad Nacional Francesa
* Palabras pronunciadas durante las honras fúnebres, Iglesia La Inmaculada Concepción del Chicó, diciembre 21 de 2010. Bogotá, D.C.

Dr. Efraím Otero Ruiz: Ex ministro de Salud, Miembro Emérito de la ACMI, Presidente de la Sociedad Colombiana de Historia de la Medicina, Bogotá, D.C.

E-mail: secretaria_anm@yahoo.com.mx Recibido: 21/I/2011 Aceptado: 17/II/2011 
de dicha especialidad, lo mismo que a la Francesa de Gastroenterología y al Círculo André Lambling, del que sería Fundador en 1981 y poco después su Presidente, distinción extraordinaria para un joven especialista proveniente de estas latitudes. A su regreso a Bogotá además como destacado internista, fue fundador en 1967 de la cátedra de Gastroenterología en el Hospital de San Juan de Dios, siguiendo de ahí en adelante por riguroso concurso a ocupar los cargos de Instructor Asociado, Profesor Asistente, Profesor Asociado y finalmente Profesor titular de dicha cátedra a partir de 1998. Pero en el curso de esa luminosa trayectoria ya había ocupado los cargos de Presidente de la Asociación Colombiana de Medicina Interna entre 1986 y 1988 y entre 1996 y 1998 había sido designado como Decano de la Facultad de Medicina de la Universidad Nacional, cargo que desempeñó con lujo de competencia a través de épocas agitadas y con frecuencia difíciles. De allí pasaría a ocupar la Presidencia de la Asociación Colombiana de Gastroenterología entre 1999 y 2001, asociación que lo designó como Presidente de su $38^{\circ}$ congreso celebrado en Medellín a finales de 2001.

Oigamos lo que sobre él escribió en 2010 en la Revista de la Academia ese maestro de educadores y de cirujanos que es José Félix Patiño: "Jaime es uno de los más brillantes profesionales egresados de la Universidad Nacional, con estudios de especialización en París en el campo de la gastroenterología. Tiene un hondo sentido de la responsabilidad social y una ejemplar vocación académica. Es un verdadero pionero. Bien recuerdo, hace ya decenios, su protagonismo en el inicio de la endoscopia digestiva y del intervencionismo endoscópico sobre la vía biliar en el país. Fue Jaime Campos quien primero logró extraer un cálculo impactado en la ampolla de Vater; lo sé, porque lo hizo en uno de mis pacientes del Hospital de La Samaritana que había sido trasladado a la Clínica de Marly".

Desde su Decanatura había mostrado inusitado interés por orientar a su alma mater por los novedosísimos aspectos de la telemedicina. Destacándose a partir de 2000 como el Fundador del Centro de Telemedicina de la Universidad Nacional, que desde entonces se ha proyectado como vehículo de consulta y de enseñanza hasta las regiones más apartadas de Colombia. Ya desde 1998 había sido designado como Profesor Honorario y desde 1999 como Profesor Especial de la Facultad de Medicina, en parte como homenaje al desempeño de su cátedra y a los casi 90 trabajos científicos publicados en temas de su especialidad. Durante su carrera científica llegó a ser Correspondiente de la Academia Nacional de Medicina y miembro de seis sociedades o asociaciones científicas colombianas, habiendo sido Fundador y Presidente de una de ellas, como fue la de Endoscopia Digestiva, y de seis extranjeras, figurando también como Fundador de la Sociedad Interamericana de la misma disciplina. Aunque miembro muy activo del American College of Physicians y de las Sociedades Americanas de Endoscopia Gastrointestinal y de Medicina Interna (antes de la era del computador, yo siempre me escabullía a su consultorio para tratar de hojear los Annals of Internal Medicine) siempre miró a su "cara Lutecia" como el más alto pedestal de donde bullían casi todas sus inquietudes científicas e intelectuales. Al fin y al cabo no sólo ella lo había formado sino que lo había distinguido egregiamente como Caballero de la Orden $\mathrm{Na}-$ cional del Mérito de Francia y como Oficial de la Orden de las Palmas Académicas, fundada por Napoleón Bonaparte en 1808 , distinciones de las que nunca hizo alarde y que hizo conocer sólo del grupo de sus cercanos amigos.

Por eso yo le decía, entre chiste y chanza, que bastaba recordarle el poema de José Umaña Bernal "Cuando yo digo Francia..." para que se le iluminaran los ojos y comenzara a planear su próximo viaje anual o bianual, a la capital del mundo, donde él y Myriam eran acogidos sin descanso por sus entrañables amigos franceses.

Resulta difícil separar, en estos momentos elegiacos, el Jaime Campos científico del Jaime Campos humano en la más excelsa acepción de la palabra. Fuimos amigos por más de 40 años y hasta hace menos de uno, cuando decidió cerrarlo, fuimos vecinos de puerta de consultorio en la A.M.A. (Fundación Santa Fe de Bogotá), donde permanecimos cercanos por un cuarto de siglo. Proveniente de Popayán donde, según Juan Jacobo Muñoz "se rumiaban tradiciones en endecasílabos" los años de vida parisina le habían añadido a su personalidad un ademán algo nihilista y hasta escéptico en que, sobre el hecho cotidiano o profesional privaba, la expresión del "causseur", un poco inquisitivo e incómodo y dispuesto a mofarse de las situaciones que lo preocupaban o hasta lo exasperaban. Ello, unido a su aguda inteligencia, lo colocaban en situación preponderante y ventajosa sobre los que lo rodeaban. Pero sin que perdiera la sindéresis ni variara el tono de voz de sus apuntes o comentarios, que al final terminaban siendo acogidos por la mayoría. En el trasfondo relucía un socialismo desvelado y sincero, probablemente también de origen parisino, en que bullía su preocupación por la transformación socioeconómica del país, pero sin falsas posturas y sin melodramas. Ello se deja entrever en algunos de los ensayos que escribió sobre las proyecciones de la medicina interna, o la gastroenterología. Como cuando escribía en 2006 su ensayo introductorio al volumen "La Medicina Interna en Colombia": "la aceptación de una carencia en nuestro conocimiento constituye un progreso fundamental del mismo. Mientras el conocimiento científico sea ciego ante el papel que desempeña en la sociedad y el lugar que ocupa en ella, continuará aportándole al poder medios de opresión y muerte. La conciencia de este papel es necesaria para que fructifiquen sus ventajas y sus posibilidades de liberación". O cuando hablaba sobre la importancia de la telemedicina para tratar de nivelar por lo alto las deficiencias en la accesibilidad o en la calidad misma de los servicios médicos, tema este que ocupó, como vimos antes, los últimos decenios de su vida. Oigamos lo que sobre ésta decía en marzo de 2010 a raíz de la presen- 
tación del programa en la Academia Nacional de Medicina: "la Telesalud aparece hoy en día como ineludible en su complemento de la prestación de los servicios de salud, por la inequidad existente y en aumento en nuestra sociedad, especialmente en las regiones rurales y distantes de nuestras capitales, constituyéndose además en un factor de integración de las poblaciones marginadas y diversificadas en el plan étnico, sociocultural y fundamentalmente arraigadas a su medio natural. Además favorece y facilita la formación continuada del personal de salud distante, corrigiendo así su aislamiento”. Pregunto yo: ¿qué voz, como la suya, nos acompañará en los actuales momentos de crisis de la salud colombiana?.

Pero además su vida personal y profesional como lo atestiguan las caras que hoy nos rodean, fue un generoso y perenne tributo a la amistad. No sólo la que brindaba a sus innumerables pacientes sino la que supo dispensar a sus colegas, amigos y colaboradores. Ya fuera como decano, o como presidente de sociedades y asociaciones, uno sabía que contaba con la presencia de Jaime en los momentos más difíciles y que, por encima de cambios de posición o de puntos de vista diferentes, sabía que podía contar por encima de todo con el amigo, cuya presencia se destacaba aun en los más intrincados y disímiles vericuetos profesionales y que no variaba con el clima de opinión ni con las diversas actitudes personales. Por todo ello, como lo dijo Patiño, "por su espíritu pionero y por su carácter visionario: Jaime es un ejemplo para la medicina colombiana".

Todo ello hace más absurda y más desgarradora esta separación. Bien saben Myriam, sus hijos, todos los aquí presentes, que, como lo decía ayer uno de sus amigos, este no es un "adiós" sino un "hasta luego", en que para todos, los que hemos venido aquí esta mañana, quedará resonando la presencia del compañero cuya existencia, que hoy nos parece a todos fue demasiado corta, seguirá para siempre iluminando lo que queda de nuestras vidas. 